Д-р техн. наук А.П. Фалендиш, канд. техн. наук Г.Л. Ватуля

\title{
ДО ПИТАННЯ РАЦІОНАЛІЗАЦІЇ КОНСТРУКЦІЇ КОМБІНОВАНИХ СИСТЕМ
}

\begin{abstract}
Вступ. Сучасний стан техніки будівництва надає можливість використання прогресивних розрахункових схем, в тому числі комбінованих, при будівництві різних транспортних споруд. Процес проектування прогонових будов мостів, який базується на варіативних методах оптимального проектування та комп'ютерного моделювання, дозволяє значно покращити показники матеріалоємності, вартості та трудомісткості будівництва. Таким чином, дослідження які направлені на розвиток зазначених питань, та їх практичне використання $є$ актуальним завданням.
\end{abstract}

Мета досліджень. У даній роботі, що $\epsilon$ розвитком досліджень $[1,2]$, викладаються питання раціоналізації конструкцій статично визначної сталебетонної шпренгельної балки прогонової будови пішохідного моста і статично невизначної шпренгельної балки покриття. Включення шпренгеля в роботу балки $є$ ефективним засобом для збільшення іiі несучої здатності, жорсткості і у багатьох випадках економічності. Подібне конструктивне рішення використовується як при створенні нових, так і при посиленні існуючих конструкцій. Раціональні конструкції досягаються шляхом варіації розташування розпірок між шпренгелем і верхнім поясом $x$ і величин стріл $f_{1}$ та $h_{1}$.

Основний матеріал досліджень. Розглянемо сталебетонну шпренгельну балку прогонової будови пішохідного моста. На балку (рис. 1) діють постійне рівномірно розподілене навантаження $q-$ від власної ваги (рис. 1,б) конструкції i тимчасове навантаження $p$ від пішоходів (рис. 1,г). У зв'язку з тимчасовим рухомим навантаженням зусилля від нього, так як і від постійного (нерухомого) навантаження, визначаємо за допомогою ліній впливу. Небезпечними 3 погляду міцності балки будуть: переріз $\xi$ - де виникає додатний максимальний згинальний момент, і переріз 1(2) - у місці примикання розпірки, де виникає найбільший від'ємний момент.

На рис.1 показані схеми завантаження ліній впливу $M_{x}$ і $M_{\xi}$ для одержання відповідно найбільшого від'ємного і додатного моментів

$$
M_{\xi}=\frac{2 x \xi l-\xi^{2}(l+2 x)}{2(l+2 x)}(p+q)-\frac{\xi l^{2}(l-2 x) q}{8 x(l+2 x)}
$$

Для знаходження перерізу $\xi$, де згинальний момент $M_{\xi}$ досягає максимуму, досліджуємо функцію (1) на екстремум, $d M_{\xi} / d \xi=0$. В результаті отримаємо

$$
\xi=\frac{8 x^{2} l(p+q)-l^{2}(l-2 x) q}{8 x(l+2 x)(p+q)}
$$

Підставимо тепер (2) у (1) і знайдемо максимальний додатний момент 
$M_{\xi, \text { max }}=\frac{l^{2}}{128 x^{2}(l+2 x)^{2}(p+q)}\left[8 x^{2}(p+q)-l(l-2 x) q\right]^{2}$.

a)

б)

$\begin{array}{llll}A & 1 & C & 2\end{array}$

в)

d)

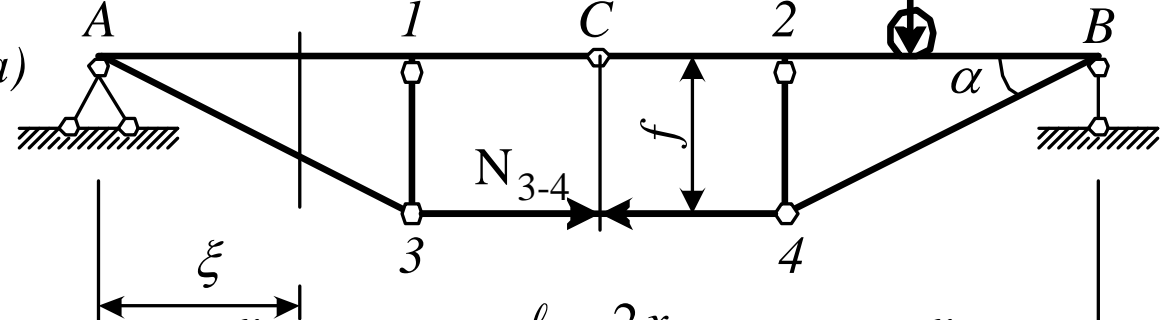

$\ell-2 x$ $x$

$\left\{\begin{array}{l}\frac{t \downarrow \downarrow t}{} \frac{x}{2 l}(l-2 x) \\ \hline \downarrow\end{array}\right.$

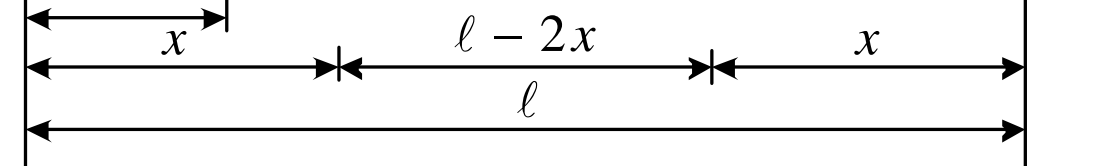

e)

ж)

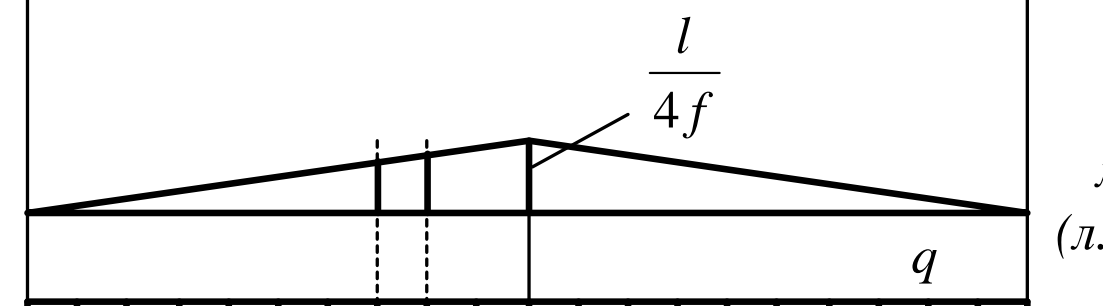

л.в. $H$

$\left(\right.$ л.в. $\left.N_{3-4}\right)$

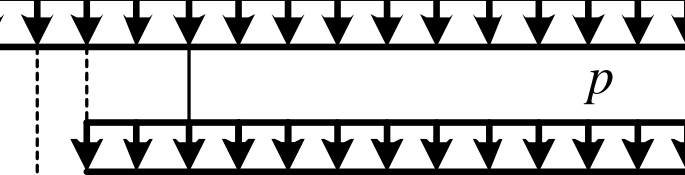

2)

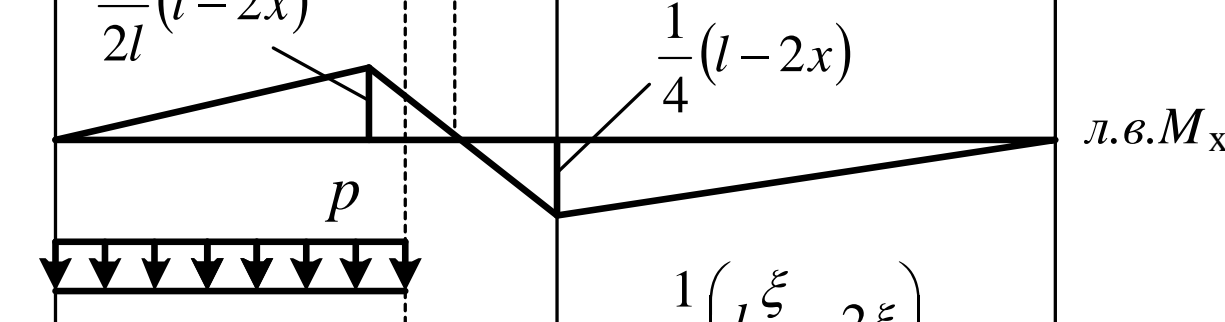

ת.6. $M_{\mathrm{x}}$

л.8. $M_{\xi}$

Рис. 1. Розрахункова схема статично визначної шпренгельної балки (а), ліній впливу $H, M_{x}, M_{y}$

Відповідна максимальному додатному моменту (3) поздовжня сила визначається 3 такого виразу: 


$$
N_{\xi}=-\frac{l^{2}}{8 f(l+2 x)^{2}}\left[8 x^{2}(q+p)+\left(l^{2}+4 x(l-x)\right) q\right]
$$

Максимальний від'ємний момент у місці примикання розпірки до сталебетонної балки (точки 1(2) на рис. 1,a)

$$
M_{x}=-\frac{(1-2 x)}{8(l+2 x)}\left[q\left(l^{2}-4 x^{2}\right)+p l^{2}\right]
$$

Поздовжня сила в цьому ж перерізі

$$
N_{x}=-\frac{q l^{2}}{8 f}\left[1+\frac{p}{q}\left(1-\frac{8 x^{2}}{(l+2 x)^{2}}\right]\right.
$$

Зусилля в елементах шпренгеля (рис.1,a) дорівнюють

$$
N_{3-4}=H=\frac{(q+p) l^{2}}{8 f} ; N_{A-3}=N_{4-B}=H \sqrt{1+\left(\frac{f}{x}\right)^{2}} ; N_{2-3}=-H \frac{f}{x} \text {. }
$$

Аналіз отриманих рівнянь показує, що згинальні моменти $M_{\xi}(3), M_{x}(5)$ не залежать від стріли $f$ шпренгеля. Від цієї величини залежать поздовжні сили (4), (6) у перерізах балки i зусилля в елементах шпренгеля (7).

Найбільш часто застосовуваним критерієм оптимальності інженерної конструкції $є$ умова мінімальності іiі маси при обмеженнях, що визначають необхідні характеристики міцності i жорсткість. Однак такий шлях розв'язання задачі $\epsilon$ досить трудомістким. Використаємо інший, більш простий критерій, що у достатній мірі еквівалентний умові мінімуму маси. Таким критерієм, який, до того ж, легко реалізується для даної конструкції пішохідного моста, є рівноміцність балки в двох перерізах $x$ і $\xi$ (див. рис. 1,a).

Кроковим перебором значень $x$ при заданих постійному i тимчасовому навантаженнях визначимо шукане положення розпірки, що відповідає близьким за абсолютною величиною моментам (5) i (3) і поздовжнім силам.

Маючи значення моментів i поздовжніх сил (4), (6), за методикою, викладеною в [3, 4], будуємо розрахункові криві $\mathrm{N}-\mathrm{M}$, що обмежують зону несучої здатності сталебетонного елемента заданої довжини в діапазоні знайдених зусиль, які характеризуються згином, позацентровим стиском (рис. 2,a).

Маючи набір розрахункових кривих, легко підібрати необхідні розміри перерізу $a, b, \delta$. На рис. 2,б наведені розміри перерізу верхнього поясу сталебетонної шпренгельної балки прогоном $l=16$ м. Навантаження на прогонову будову моста: постійне $q=5$ кН/м, тимчасове $p=6,4$ кН/м. Ширина моста -3 м. 
Розглянемо сталебетонну шпренгельну балку покриття. Розрахункова схема балки покриття показана на рис. 3. Рівномірно розподілене навантаження $q=7,01$ кН/м, згідно з СНиП II-6-74, включає власну масу конструкції і сніговий покрив.
На відміну від задачі щодо оптимізації прогонової балки пішохідного моста, сталебетонна шпренгельна балка покриття (рис. 3) статично невизначна. Будь-яке зусилля в ній залежить від жорсткостей елементів. Тому розв'язання виконуємо в послідовних наближеннях при кроковому навантаженні. a)

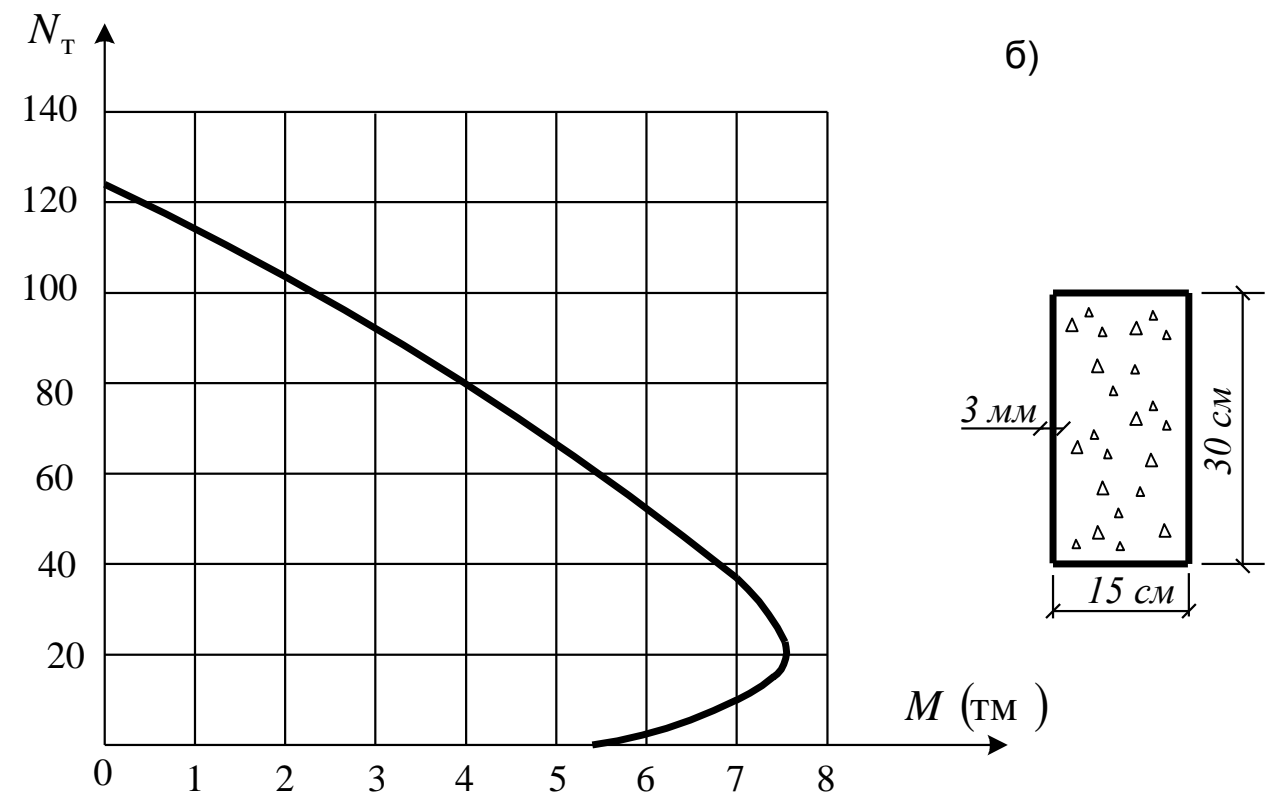

Рис. 2. Розрахункова крива, яка обмежує зону несучої спроможності сталебетонного елемента розрахункової довжини

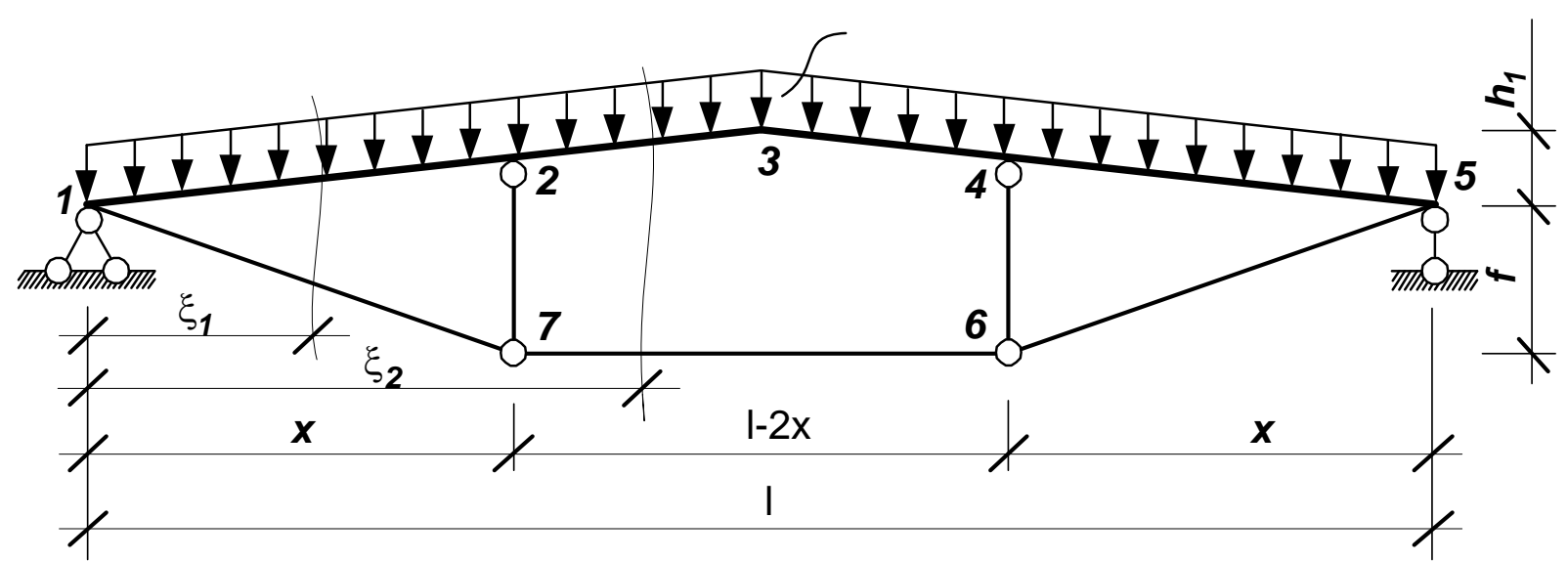

Рис. 3. Розрахункова схема статично невизначної шпренгельної балки покриття 
Ітераційний процес включає внутрішній і зовнішній цикли. $\mathrm{y}$ внутрішньому циклі уточнюються жорсткості перерізів верхнього поясу сталебетонної балки $[3,4]$. У зовнішньому циклі визначаються зусилля в зайвому зв'язку і внутрішні сили в заданій системі при відомих $q, x, h_{l}, f . \mathrm{У}$ нульовому наближенні жорсткості максимальні i визначаються 3 припущення пружних властивостей матеріалів. Пружне рішення записується в такому вигляді:

$$
\begin{aligned}
& N_{l}=-\left(\frac{\left(x l-2 h_{1} f\right) X_{1}}{x \sqrt{l^{2}+4 h_{l}^{2}}}+\frac{q l h_{1}}{\sqrt{l^{2}+4 h_{l}^{2}}}\right) \\
& M_{\xi 1 \max }=\frac{q \xi_{1}\left(l-\xi_{1}\right) \sqrt{l^{2}+4 h_{1}}}{2 l}-X_{1} \frac{\left(2 x h_{1}+\mid f\right) \xi_{1}}{x \mid} ; \\
& N_{\xi 1}=-\left(\frac{\left(x l-2 h_{1} f\right) X_{1}}{x \sqrt{l^{2}+4 h_{1}^{2}}}+\frac{q h_{1}\left(l-2 \xi_{1}\right)}{\sqrt{l^{2}+4 h_{1}^{2}}}\right) \\
& M_{2}=\frac{q x(l-x) \sqrt{l^{2}+4 h_{1}}}{2 l}-X_{1} \frac{\left(2 x h_{1}+l f\right)}{l} \\
& N_{2}^{\text {лів }}=-\left(\frac{\left(x l-2 h_{1} f\right) X_{1}}{x \sqrt{l^{2}+4 h_{1}^{2}}}+\frac{q h_{1}(L-2 x)}{\sqrt{l^{2}+4 h_{1}^{2}}}\right) \\
& N_{2}^{n p}=-\left(\frac{l X_{1}}{\sqrt{l^{2}+4 h_{1}^{2}}}+\frac{q h_{1}(L-2 x)}{\sqrt{l^{2}+4 h_{1}^{2}}}\right) \\
& M_{\xi 2 \max }=\frac{q \xi_{2}\left(l-\xi_{2}\right) \sqrt{l^{2}+4 h_{1}}}{2 l}-X_{1}\left(\frac{2\left(l h_{1}-2 x h_{1}\right)\left(\xi_{2}-x\right)}{l(l-2 x)}+\frac{\left(2 x h_{1}+l f\right)}{l}\right) \text {; } \\
& N_{\xi 2}=-\left(\frac{l X_{1}}{\sqrt{l^{2}+4 h_{1}^{2}}}+\frac{q h_{1}\left(L-2 \xi_{2}\right)}{\sqrt{l^{2}+4 h_{1}^{2}}}\right)
\end{aligned}
$$




$$
\begin{aligned}
& M_{3}=\frac{q l \sqrt{l^{2}+4 h_{1}}}{8}-X_{l}\left(h_{l}+f\right) ; \\
& N_{3}=-\frac{l X_{1}}{\sqrt{l^{2}+4 h_{l}^{2}}} ; \\
& \text { де } \xi_{1}=\frac{l}{2}-\frac{X_{l}\left(2 x h_{1}+l f\right)}{q x \sqrt{l^{2}+4 h_{l}^{2}}} ; \\
& \xi_{2}=\frac{l}{2}-\frac{2 X_{1} h_{1}}{q \sqrt{l^{2}+4 h_{l}^{2}}} ; \\
& X_{1}=f\left(E A, \quad E J, \quad h_{l}, \quad f, \quad x\right) \text { - зайве невідоме. }
\end{aligned}
$$

Процес послідовних наближень організовується таким чином, що для кожного n-го наближення здійснюється кроковий перебір значень $x, h_{l}, f$, визначається несуча здатність (див. рис. 2) балки в перерізах $\xi_{1}, x, \xi_{2}, l / 2$, виконується аналіз отриманих рішень, коректуються дані для наступного наближення.
Висновки. В результаті розрахунку оптимальні параметри балки покриття, що характеризують рівноміцність у відзначених вище чотирьох перерізах, вийшли такими:

$$
x=5,17 \mathrm{м}, \quad h_{1}=1 \mathrm{M}, f=2 \mathrm{M} .
$$

Характеристики перерізу: елементи 2-7, 4-6, - $2\llcorner 63 \times 4$ елементи 1-7, 7-6, 6-5 - $2\llcorner 63 \times 4$ верхній пояс: обойма $\square 140 \times 100 \times 4$, бетон класу C30/35.

\section{Список літератури}

1. Основы расчета и проектирования комбинированных и сталебетонных конструкций [Текст] / Э.Д. Чихладзе , Г.Л. Ватуля, Ю.П. Китов [и др.]; под ред. Э.Д. Чихладзе. - К.: Транспорт Украины, 2006. - 104 с.

2. Ватуля, Г.Л. Несущая способность сталебетонных балок прямоугольного сечения, усиленных шпренгелем [Текст]: дис... канд. техн. Наук / Г.Л. Ватуля. - Харьков, 1999. - 160 с.

3. Чихладзе, Э.Д. Расчет сталебетонных элементов прямоугольного сечения на прочность при изгибе и внецентренном сжатии [Текст] / Э.Д. Чихладзе, А.Д. Арсланханов // Известия вузов. Строительство. - 1992. - № 1. - С. 6-10.

4. Чихладзе, Э.Д. Расчет сталебетонных элементов прямоугольного сечения на прочность при изгибе и внецентренном сжатии [Текст] / Э.Д. Чихладзе, А.Д. Арсланханов, А. Салам // Строительная механика и расчет сооружений. - 1992. - № 3. - С.9-17.

Ключові слова: прогонова будова, раціоналізація конструкції, лінія впливу, шпренгельна балка, критерій оптимальності. 


\section{Аннотації}

У роботі розглядаються питання раціоналізації конструкцій статично визначної сталебетонної шпренгельної балки прогонової будови пішохідного моста і статично невизначної шпренгельної балки покриття.

В работе рассматриваются вопросы рационализации конструкции статически определимой шпренгельной балки пролетного строения пешеходного моста и статически неопределимой шпренгельной балки покрытия.

The author describes the structure rationalization methodology of statically determinate steel concrete braced beam of pedestrian bridge span and statically indeterminate braced roof beam. 